\title{
ANÁLISE DA UTILIZAÇÃO PELA CLIENTELA DE UMA UNIDADE AMBULATORIAL DA SECRETARIA DA SAÚDE DO MUNICÍPIO DE SÃO PAULO, SP (BRASIL)*
}

\author{
Oswaldo Yoshimi Tanaka** \\ Cornélio Pedroso Resenburg**
}

TANAKA, O.Y. \& ROSENBURG, C.P. Análise da utilização pela clientela de uma unidade ambulatorial da Secretaria da Saúde do Município de São Paulo, SP (Brasil). Rev. Saúde públ., S. Paulo, 24:60 $-8,1990$.

RESUMO: Apresenta-se proposta para integração das ações de assistência médica individual de caráter curativo com as açōes de assistência médico-sanitária. Foram estudados dois serviços de assistência à saúde do Município de São Paulo (Brasil). Partindo-se do pressuposto de que qualquer ação no campo da saúde depende da participação da comunidade, buscou-se conhecer a forma pela qual a população recebe e utiliza os serviços localmente integrados. Assim, foram coletadas junto à clientela de ambos os serviços, informações tais como: motivo de procura, resolutividade, satisfaçāo e outras, obtidas por meio de formulários. A análise das características das queixas, da resolutividade e da satisfação referida pela clientela, do objetivo e do processo de trabalho desses serviços, leva à conclusão de que eles são utilizados de forma seletiva pela clientela, visando, principalmente, ao atendimento de suas necessidades diretamente relacionadas à resolução das manifestações de doença.

DESCRITORES: Cuidados primários de saúde. Necessidades e demanda de serviços de saúde. Satisfação do paciente.

\section{INTRODUÇÃO}

A situação atual da prestação de serviços de saúde à população brasileira, particularmente no Estado de São Paulo, apresenta-se de forma complexa, envolvendo um mosaico de instituições desse setor. Acompanhando o momento político e econômico do País, o setor saúde encontra-se em fase de transição, devido, sobretudo, à necessidade de redefinição do papel do Estado, com base nas novas condições sócio-econômicas e políticas emergentes, as quais acarretam necessários ajustes dos setores sociais do País.

Contudo, a situação atual dos serviços de saúde resulta de diretrizes políticas anteriores, que configura um quadro específico, o qual só poderá ser compreendido ao se recuperarem a trajetória e a história dessas políticas, resgatando-as com a maior abrangência possível, contemplando principalmente a integração de serviços. Para melhor compreensão dessas políticas, faz-se necessário retomar parcialmente o histórico de saúde no País.

Iniciado pela década dos 20 , verifica-se que nesta é introduzido no Brasil uma nova perspectiva para a saúde pública baseada na assistência médico-sanitária e que seria operacionalizada pelo centro de saúde com enfoque eminentemente preventivo, dando inf́cio ao processo de separação entre as ações médico-sanitárias, de caráter preventivo, e as ações de assistência médica individual, de caráter curativo ${ }^{18,21}$. Enquanto que a assistência médica individual é incorporada na criação das Caixas de Aposentadoria e Pensões (CAP) que aparecem em 1923 com a Lei Eloi Chaves?

Esse modelo dicotômico se mantém inalterado até o início da década de 50 , quando os serviços já bastante ampliados de assistência médica individual se modificam pela tecnificação do ato médico e pela incorporação de novas medidas nas terapêuticas, acarretando mudança substancial no atendimento prestado pelo sistema previdenciário ${ }^{2}$.

Assim, da década de 50 até meados da de 60 , verifica-se aumento progressivo de assistência médica individual rcalizada pelo sistema previdenciário, enquanto se observa praticamente uma estabilização das ações de saúde pública. O mecanismo compensatório social frente às alterações do modelo econômico era rcalizado pela política previdenciária por meio de ações de assistência médica individual de caráter curativo, em detrimento de ações de saúde pública, que se apresentavam limitadas pela política do Estado para o setor.

A partir da década de 70 , há uma progressiva expansão de cobcrtura de assistência médica pelo sistema previdenciário, que passa a incorporar

* Extraído da tese de doutorado intitulada "Análise da utilização dos serviços do Posto de Assistência Médica e do Pronto Atendimento do Jardim São Jorge no Municipio de São Paulo", por meio de estudo da clientela usuária, apresentada à Faculdade de Saúde Pública em 1988.

* Departamento de Saúde Materno-Infantil da Faculdade de Saúde Pública da Universidade de São Paulo - Av. Dr. Arnaldo, 715 - 01255 - São Paulo, SP - Brasil. 
trabalhadores nåo formalmente vinculados ao processo de produção. A progressiva expansão de cobertura e dos gastos em saúde, acrescida da crise político-econômica decorrente do fim do "milagre econômico", em 1972, levou à uecessidade de ajustes no sistema, os quais ocorreram em 1974, com a criação do Plano de Pronta Ação - PPA e do Ministério da Previdência e Assistência Social MPAS ${ }^{17}$.

Essas medidas permitiriam atender rapidamente à crescente demanda decorrente da piora das condiçzes de vida, principalmente da população urbana que se encontrava alijada do mercado de trabalho formal, devido ao processo econômico recessivo do País.

Atingida essa fase de expansão, o Estado passa a ter preocupação com a organização global da prestação de serviços de saúde. Para tanto, é promulgada a Lei $n^{2} 6.229 / 75$, criando o Sistema Nacional de Saúde ${ }^{6}$. Este Sistema procurava coordenar as açōes da medicina previdenciária, que já haviam adquirido autonomia em relação à política nacional formulada pelo Ministério da Saúde.

Durante esse período foi mantida a autonomia da política previdenciária e seu papel social compensador, não alterando significativamente o modo de produção da assistência médico-hospitalar privada dominante, voltado para a manutenção da saúde individual da classe trabalhadora, enquanto a saúde pública atendia à camada da população menos favorecida, por meio de programas de assistência médico-sanitária ${ }^{14}$.

No início de 1980 foi realizada a VII Conferência Nacional de Saúde ${ }^{7}$, cujo tema básico era a extensão das açoes de saúde através de serviços básicos, visando aos cuidados primários de saúde, reforçando as propostas políticas da reunião de Alma-Ata, ocorrida em $1978^{5}$. Nessa Conferência foram lançadas as bases para o Programa Nacional de Serviços Básicos de Saúde - PREVSAUDE, cujo primeiro anteprojeto foi elaborado em agosto de $1980^{16}$.

As propostas do PREV-SAÚDE eram tão ambiciosas em suas metas que a oposição criada pclas entidades privadas, bem como por parte de instituiçōes públicas, principalmente ligadas à Previdência Social, levaram a modificaçōes substanciais da proposta inicial, a qual no final se restringiu a uma reordenacăo no setor público prestador de serviços de saúde, não fazendo qualquer menção ao setor privado e definindo como áreas de abrangência as localidades de maior carência e grupos sociais mais desprotegidos, perdendo completamente o propósito inicial.

Como resposta governamental à proposta do PREV-SAÚDE foi elaborado pelo CONASP o Plano de Reorientação da Assistência à Saúde no âm- bito de Previdência Social ${ }^{15}$.

Dentre os vários programas contidos no Plano, destacam-se as Açôes Integradas de Saúde (AIS), que tinham como objetivo universalizar e propiciar o atendimento ambulatorial e hospitalar, tornando os serviços dos diferentes níveis de complexidade mais acessíveis à população.

Em síntese, as transformaçōes planejadas no início da década de 80 , que foram iniciadas com a formulação de uma proposta tecnicamente bem elaborada e "ambiciosa", de mudança no modo de produção do setor saúde, não tiveram o necessário respaldo político para a sua efetivação.

O sistema previdenciário, que já apresentava sinais de recrudescimento de seus gastos após os ajustes administrativos efetuados ao final da década de 70, propõe as AIS como um novo plano de reordenamento do setor público prestador de serviços em nível estadual e municipal. A partir da implantação dessa estratégia, observou-se uma diminuição do papel da saúde pública nas definiçōes políticas do setor saúde, pois, ao se canalizarem recursos financeiros para esses setores, propiciouse a mudança do papel institucional dessas instâncias, incorporando-as como prestadoras de assistência médica individual a uma população universalizada pela Previdência Social.

Tem-se, como resultante dessas distintas políticas, implementadas desde o começo do século neste País, uma situação de segmentação dos serviços de saúde e, conseqüentemente, da populacão que se utilizava desses serviços.

Essa segmentação ocorreu uma vez que a saúde pública tem-se caracterizado por açסes coletivas visando ao controle do agente ou do meio ambiente, enquanto a medicina previdenciária em contrapartida, desde a sua origem, aparece ligada ao modo de produção, atuando nos problemas de saúde do indivíduo ligado diretamente à sua forma de inserção no mercado de trabalho.

Portanto, no momento atual, em que se retoma o conceito de cidadania ${ }^{19}$ e se busca oferecer os serviços de saúde de forma a garantir a eqüidade e conhecendo parcialmente o processo histórico da saúde pública e da medicina previdenciária que resultou na segmentação exposta, faz-se necessário conhecer de que forma ocorre a integração das açōes de assistência médica individual aos serviços de saúde püblica, uma vez que a integração é a estratégia principal para mudança no setor.

Para aprofundar os conhecimentos sobre essas questões, que se considera primordial para a comprcensão do processo de integração dessas atividades e conseqüente mudança do papel institucional dos serviços públicos de assistência à saúde, foi escolhido um Posto de Assistência Médica com um 
Pronto Atendimento integrado (PAM-PA) da Secretaria de Higiene e Saúde do Munícipio de São Paulo (SHS), para estudo desse processo de integração. Uma unidade desse tipo permite o estudo concomitante das atividades de assistência médico-sanitária e de assistência médica individual de caráter curativo.

O Presente trabalho objetivou: conhecer as características individuais e sócio-econômicas da clientela que utiliza os serviços de Pronto Atendimento e o Posto de Assistência Médica; analisar o tipo e a característica do motivo pelo qual a clientela procura e utiliza esses serviços; analisar a resolutividade e a satisfação referida pela clientela e os possíveis fatores que intervêm nesse resultado; analisar as diferentes formas de utilização dos serviços pela clientela com relação aos objetivos e ao processo de trabalho dos mesmos.

\section{MATERIAL E METODO}

Como já referido, será estudado o PAM-PA Jardim São Jorge da SHS, localizado na zona Oeste do Município de São Paulo, no distrito de paz do Butantã.

O Butantã tem uma extensão geográfica de $253,86 \mathrm{~m}^{2}$ e uma população estimada, para 1985 , de 408.305 habitantes. Localiza-se na região limítrofe do Município e faz divisa com Taboão da Serra, Cotia e Itapecerica da Serra.

A área de abrangência do PAM-PA compreende uma população de, aproximadamente, 140.000 habitantes, residentes em 10 núcleos habitacionais circunjacentes. Em um levantamento preliminar da produção de serviços dos últimos 12 meses, anterior à pesquisa, verificou-se que a média mensal era de 1.732 consultas médicas no PAM e de 6.564 consultas médicas no PA, sendo que acima de $80 \%$ da demanda provinha de 4 conjuntos habitacionais: Jardim São Jorge, Jardim Arpoador, Jardim João XXIII e Jardim Cambará, razão pela qual essa foi considerada a população alvo do presente estudo.

As variáveis definidas para estudo foram agrupadas em 3 grupos:

a) características individuais e sócio-econômicas: idade, sexo, domicilio, tempo de residência na região, ocupação do chefe da familia, renda familiar "per capita", situação previdenciária do chefe da familia;

b) motivo de procura aos serviços: motivo (queixa) de procura apresentado pela clientela, análise das condutas prescritas, identificação das causas atribuídas pela clientela à evolução apresentada, recursos de assistência médica utilizados para a mesma queixa e satisfação pessoal pelo atendimento recebido.
Para definição da amostra foi realizado um pré-teste com 20 clientes de ambos os serviços. Em função dos dados encontrados e os tipos de variáveis utilizados, e considerando uma imprecisão de $10 \%$ com probabilidade de $95 \%$ e estimando uma perda de casos de $20 \%$, definiu-se que o tamanho de amostra deveria ser de 110 clientes no PAM e 114 no PA. A amostra foi coletada utilizando-se da escolha sistemática aleatória.

As informações referentes às características individuais e sócio-econômicas e o motivo de procura aos serviços foram coletados por meio da aplicação de um formulário no próprio PAM-PA, por entrevistador treinado, previamente ao atendimento médico ${ }^{3}, 4$.

As informaçōes referentes à resolutividade foram coletadas em domicílio, num intervalo de 7 a 14 dias após o atendimento, por meio da aplicação de um segundo formulário pelo mesmo entrevistador treinado.

Durante todo o período de aplicação dos formulários, que ocorreu de outubro de 1985 a março de 1986, foi feita supervisão diária do trabalho de campo, que consistia na conferência de cada formulário preenchido.

Os formulários foram aplicados em 122 clientes do PAM e 127 clientes do PA.

Os dados coletados foram consolidados e tabulados manualmente, cruzando-se as variáveis julgadas pertinentes ao estudo de acordo com os objetivos definidos.

Para a análise estatística de dados foram utilizados testes não paramétricos. $O$ teste de $\chi^{2}$, foi utilizado na análise de variáveis e o teste " $t$ " para a comparação de médias. Estes foram empregados sempre que necessário, utilizando-se o nível de significância de $5 \%$.

\section{RESULTADOS E ANÁLISE DOS DADOS}

\section{Características Individuais e Sócio-Econômicas da Clientela}

A clientela do PAM e do PA mostram uma distribuição por faixa etária bastante semelhante, sendo formada predominantemente por crianças menores de 10 anos e adultos do sexo feminino, nåo havendo diferença significativa entre ambos os serviços. As crianças de 10 anos representam em torno de $60 \%$ e as mulheres, em torno de $18 \%$ da amostra.

Em termos de renda familiar "per capita" de ambas as clientelas, em relação ao salário mínimo (SM) vigente na época, mostra a Tabela 1 que a moda da distribuição se encontra entre 0,26 e 0,50 SM "per capita", indicando pertencerem elas às 
camadas sociais menos favorecidas. Observa-se ainda que $59,83 \%$ da clientela do PAM e $43,30 \%$ da clientela do PA apresentam renda familiar "per capita" abaixo de 0,50 SM; por outro lado, 2,46\% no PAM e $13,38 \%$ no PA apresentam, respectivamente, renda acima de $1,50 \mathrm{SM}$.

Apesar de ambas as clientelas apresentarem baixa renda familiar "per capita", o cálculo da renda média familiar "per capita", da ordem de $0,5615 \mathrm{SM}$ e $0,8061 \mathrm{SM}$, obtidos no PAM e no PA, mostra, quando analisados estatisticamente, diferença significativa.

Quanto à ocupação do chefe da familia, observa-se nåo haver diferença entre as clientelas de ambos os serviços. Os maiores contingentes, $87,80 \%$ no PAM e $83,46 \%$ no PA, concentram-se nas duas primeiras categorias sócio-ocupacionais, que apresentam ocupações do tipo manual, não especializada e especializada, assim como as assemelhadas.

O nível de escolaridade apresentado pelo chefe da familia foi bastante baixo, pois $59,84 \%$ do PAM e $49,60 \%$ do PA não haviam concluído quatro anos de educação básica, portanto não possuíam alfabetização básica. Essa condição estaria interferindo não somente na sua inserção na força de trabalho produtiva, mas restringiria igualmente a utilização plena dos recursos sociais disponíveis na comunidade.

A cobertura previdenciária encontrada na população analisada foi de apenas $70,0 \%$, em ambas as clientelas.

Esses dados permitem revelar a homogeneidade de ambas as clientelas bem como indicam o tipo de inserção dos mesmos numa dada estrutura de mercado de trabalho e, conseqüentemente, as condições objetivas de existência.

Em suma, observou-se que não há diferença entre a clientela do PAM e do PA, que é constituída essencialmente pela população materno-infantil, a grande maioria residente na região há mais de

\section{TABELA 1}

Número e percentagem de clientes segundo renda "per capita" e área de atendimento do PAM-PA Jardim S. Jorge - SP, no período de outubro de 1985 a março de 1986.

\begin{tabular}{lcrrr}
\hline $\begin{array}{l}\text { Renda Familiar } \\
\text { Per Capita/Mês* }\end{array}$ & $\mathrm{n}^{2}$ & PAM & $\mathrm{n}^{\mathrm{e}}$ & \multicolumn{1}{c}{ PA } \\
\hline$<0,25$ & 23 & 18,9 & 18 & 14,2 \\
$0,26-0,50$ & 50 & 41,0 & 37 & 29,1 \\
$0,51-0,75$ & 16 & 13,1 & 27 & 21,3 \\
$0,76-1,00$ & 20 & 16,4 & 14 & 11,0 \\
$1,01-1,25$ & 6 & 4,9 & 8 & 6,3 \\
$1,26-1,50$ & 4 & 3,3 & 6 & 4,7 \\
$1,51-1,75$ & 1 & 0,8 & 3 & 2,4 \\
$1,76-2,00$ & - & - & 4 & 3,1 \\
$2,01-2,50$ & - & - & 3 & 2,4 \\
$>2,51$ & 2 & 1,6 & 7 & 5,5 \\
\hline Total & 122 & 100,0 & 127 & 100,0 \\
\hline
\end{tabular}

* Em salário mínimo da época

Comparação das médias de renda familiar "per capita"

PA

média $=0.8061$ S.M.

desvio padrão $=0,779359$ S.M.

valor de $t=3,04798$

$>$ diferença significativa

$\mathrm{t}$ crítico $=1,96$

graus de liberdade $=204,303$
PAM

média $=0,5615$ S.M.

desvio padrão $=449667$ S.M. 
dois anos, com situação sócio-econômica precária concentrada nos estratos sociais mais baixos, apresentando, portanto, baixa renda, baixa escolaridade e ocupação predominantemente manual.

\section{Motivo de Procura ao Serviço}

O principal motivo de procura ao serviço, apresentado pela clientela do PAM e do PA, refere-se a queixas relacionadas predominantemente a problemas dos aparelhos digestivo e respiratório e a problemas gerais e inespecíficos. Essas três principais queixas representam $59,8 \%$ dos motivos de procura ao PAM e $80,3 \%$ ao PA (Tabela 2).

Ao analisar o tempo de duração da queixa da clientela observa-se que esse é bastante pequeno no PA, sendo que $55,9 \%$ da clientela refere aparecimento em menos de um dia e $89,0 \%$ em menos de uma semana, enquanto no PAM as queixas com aparecimento de menos de uma dia são de apenas $14,7 \%$ e em menos de uma semana de $56,5 \%$. Fato esse de se esperar, pelas características de cada área de atendimento.

TABELA 2

Número e percentagem de clientes segundo tipo de queixa ou motivo de área de atendimento do PAM-PA Jardim S. Jorge - SP no período de outubro de 1985 a março de 1986.

\begin{tabular}{|c|c|c|c|c|c|c|}
\hline \multirow{2}{*}{$\begin{array}{l}\text { Motivos ou } \\
\text { Queixas }\end{array}$} & \multicolumn{3}{|c|}{ PAM } & \multicolumn{3}{|c|}{ PA } \\
\hline & $\mathrm{n}^{2}$ & & $\%$ & $\mathbf{n}^{\circ}$ & & $\%$ \\
\hline Problemas Gerais e Inespecíficos & & 19 & 15,6 & & 21 & 16,5 \\
\hline Sintomas e Queixas & 15 & & & 18 & & \\
\hline Procedimentos Diagnósticos e preventivos & 2 & & & 3 & & \\
\hline Medicação, Tratamento e Procedimento Terapêutico & 1 & & & - & & \\
\hline $\begin{array}{l}\text { Diagnósticos e Doenças } \\
\text { Sangue Ótoãos Linfáticos Formadores do Sanque }\end{array}$ & 1 & & & - & - & \\
\hline $\begin{array}{l}\text { Sangue, Óggãos Linfáticos Formadores do Sangue } \\
\text { Medicacão, Tratamento e Procedimento Terapêutico }\end{array}$ & 1 & 1 & 0,8 & - & - & - \\
\hline $\begin{array}{l}\text { Aparelho Digestivo } \\
\text { A }\end{array}$ & & 31 & 25,4 & & 42 & 33,0 \\
\hline Sintomas e Queixas & 17 & & & 40 & & \\
\hline Procedimentos Diagnósticos e Preventivos & 4 & & & - & & \\
\hline $\begin{array}{l}\text { Encaminhamentos e outras razões } \\
\text { Diagnósticos e Doenças }\end{array}$ & 1 & & & $\bar{z}$ & & \\
\hline $\begin{array}{l}\text { Diagnósticos e Doenças } \\
\text { Olho }\end{array}$ & 9 & 3 & $4=$ & 2 & 2 & 16 \\
\hline Sintomas e Queixas & 3 & 3 & 2,0 & 2 & - & \\
\hline Ouvido & & 5 & 4,1 & & 4 & 3,2 \\
\hline Sintomas e Queixas & 5 & & & 3 & & \\
\hline Diagnósticos e Doenças & - & & & 1 & & \\
\hline Aparelho Circulatório & & 2 & 1,6 & & 4 & 3,2 \\
\hline Sintomas e Queixas & 2 & & & 3 & & \\
\hline Encaminhamentos e outras razões & - & & & 1 & & \\
\hline Sistema Músculo Esquelético & & 6 & 4,9 & & 4 & 3,2 \\
\hline Sintomas e Queixas & 6 & & & 4 & & \\
\hline Sistema Nervoso & & 2 & 1,6 & & 2 & 1,6 \\
\hline Sintomas e Queixas & 1 & & & 2 & & \\
\hline Procedimentos Diagnósticos e Preventivos & 1 & & & - & & \\
\hline Aparclho Respiratório & & 23 & 18,9 & & 39 & 30,7 \\
\hline Sintomas e Queixas & 17 & & & 16 & & \\
\hline Diagnósticos e Doenças & 6 & & & 23 & & \\
\hline Pele & & 8 & 6,6 & & 6 & 4,7 \\
\hline Sintomas e Qucixas & 8 & & & 6 & & \\
\hline Endócrinas, Metabólico e Nutricional & & 1 & 0,8 & & - & - \\
\hline Sintomas e Queixas & 1 & & & - & & \\
\hline Aparelho Urinário & & 2 & 1,6 & & 1 & 0,7 \\
\hline Sintomas e Queixas & 2 & & & 1 & & \\
\hline Gravidez, Parto, Planejamento Familiar & & 12 & 9,9 & & 2 & 1,6 \\
\hline Sintomas e Queixas & 9 & & & 1 & & \\
\hline Procedimentos Diagnósticos e Preventivos & 3 & & & - & & \\
\hline Diagnósticos e Doenças & - & & & 1 & & \\
\hline Aparelho Genital Masculino & & 1 & 0,8 & & - & - \\
\hline Sintomas e Queixas & 1 & & & - & & \\
\hline Aparelho Genital Feminino & & 4 & 3,3 & & - & - \\
\hline Sintomas e Queixas & 2 & & & - & & \\
\hline Procedimentos Diagnósticos e Preventivos & 2 & & & - & & \\
\hline Problemas Sociais & & 2 & 1,6 & & - & - \\
\hline Encaminhamento e outras razöes & 2 & & & - & & \\
\hline Total & & 122 & 100,0 & & 127 & 100,0 \\
\hline
\end{tabular}


Ao se analisarem as queixas referidas em cada grupo de sistema anatômico verifica-se, em ambos os serviços, que a febre é o motivo mais freqüente dentre os problemas gerais e inespecíficos, a diarréia e o vômito são os mais freqüentes dentre os problemas do aparelho digestivo, e a tosse, a falta de ar e a dor de garganta dentre os problemas do aparelho respiratório, sendo essas bastante semelhantes àquelas encontradas em outros trabalhos ${ }^{1,20}$.

Tendo em vista o método amostral utilizado para o PAM, dois terços da clientela estavam agendados para atendimento de rotina, conforme cronograma estabelecido. Esses estariam vindo à unidade para supervisão de saúde da qual a atividade de controle de crescimento e desenvolvimento e a detecção precoce de patologias são partes integrantes ${ }^{21}$; seria, portanto, esperada uma baixa freqüência de queixas no PAM; no entanto, $75,96 \%$ da clientela agendada nesse serviço referia problemas de saúde.

Essa alta freqüência de queixas poderia estar retratando uma alta prevalência de problemas de saúde de pequena gravidade e evolução mais longa, cuja solução poderia ser postergada.
Quanto ao diagnóstico, o mais freqüente é o de doenças do aparelho respiratório, que aparece em $45,7 \%$ no PA e $26,2 \%$ no PAM e, a seguir, as doenças infecciosas e parasitárias, com $20,7 \%$ no PA e $23,8 \%$ no PAM. Ao se analisar os diagnósticos em relação à renda familiar "per capita" observa-se que no PA as doenças do aparelho respiratório são as mais freqüentes em qualquer faixa de renda, enquanto no PAM se nota maior freqüência de doenças infecciosas e parasitárias nas faixas até 0,5 SM familiar "per capita"; acima desse nível predominam as doenças do aparelho respiratório.

Ao analisar a relação entre a queixa referida pela clientela e o diagnóstico médico efetuado, observa-se maior concordância no PA do que no PAM. Essa situação pode ser devido a que a queixa no PA, sendo mais aguda e mais evidente, esta é mais valorizada pelo médico, como foi observado em trabalhos anteriores realizados por Tanaka ${ }^{21} \mathrm{e}$ Gonçalves ${ }^{12}$.

As condutas prescritas à clientela foram obtidas por meio de verificação no prontuário do cliente; observa-se que $92,6 \%$ da clientela do PAM e $81,1 \%$ da clientela do PA apresentam prescriçōes

TABELA 3

Número e percentagem de clientes segundo tipo de serviços utilizados nos últimos 12 meses e área de atendimento do PAM - PA do Jardim S. Jorge -SP, no periodo de outubro de 1985 a março de 1986.

\begin{tabular}{|c|c|c|c|c|}
\hline Serviços & & & & \\
\hline & $n^{2}$ & $\%$ & $\mathrm{n}^{2}$ & $\%$ \\
\hline Pronto Atendimento & 13 & 10,7 & 32 & 25,3 \\
\hline Pronto Atend./outros serv.* & 3 & 2,5 & 61 & $48,0 * *$ \\
\hline Sub-Total & 16 & 13,2 & 93 & 73,3 \\
\hline $\begin{array}{l}\text { Clínica pediátrica e } \\
\text { outros serviços *** }\end{array}$ & 56 & 45,9 & 8 & 6,3 \\
\hline $\begin{array}{l}\text { Clínica médica e } \\
\text { outros serviços *** }\end{array}$ & 12 & 9,9 & - & - \\
\hline $\begin{array}{l}\text { Clínica pré-natal e } \\
\text { outros serviços }\end{array}$ & 6 & 4,9 & - & - \\
\hline Clínica pediátrica & 5 & 4,1 & 4 & 3,1 \\
\hline Clínica médica & 5 & 4,1 & 4 & 3,1 \\
\hline Clínica pré-natal & 1 & 0,8 & 2 & 1,6 \\
\hline Sub-Total & 85 & 69,7 & 18 & $14,1 * *$ \\
\hline Outros" & 2 & 1,5 & 4 & 3,1 \\
\hline Não utilizou & 19 & 15,6 & 12 & 9,5 \\
\hline Total & 122 & 100,0 & 127 & 100,0 \\
\hline
\end{tabular}

* outras atividades do PAM-PA, exceto consulta médica

* 48,03 + 14,16 = 62,19\% - correspondente à clientela do PA que utiliza serviços do PAM

* * engloba outros serviços de assistência médica do PAM 
medicamentosas, o que mostra um alto grau de "medicação"12 do atendimento médico oferecido por ambos os serviços.

Quanto à utilização dos serviços oferecidos pela unidade de saúde analisada, observa-se pela Tabela 3 que $69,7 \%$ da clientela do PAM utilizou, nos últimos 12 meses, exclusivamente seus serviços.

No caso da clientela do PA, 73,2\% utilizou esses serviços, sendo que $34,0 \%$ o fez de forma exclusiva. Portanto, a clientela do PAM utiliza com maior freqüência, de forma exclusiva, esses serviços, mostrando sua vinculação ao mesmo. No entanto, apenas uma pequena percentagem da clientela do PA os utiliza com caráter preferencial, pois a maioria se utiliza também dos serviços oferecidos pelo PAM.

\section{Grau de Resolutividade}

Ao analisar o grau de resolutividade, a primeira preocupação foi verificar a evolução da queixa, segundo a opinião da clientela de ambos os serviços. Os dados constantes da Tabela 4 mostram que $70,5 \%$ da clientela do PAM e $81,9 \%$ do PA refere melhora. A diferença encontrada entre ambos os serviços, quando submetida ao teste de $\chi^{2}$, evidencia ser ela estatisticamente significativa, sugerindo portanto ser o PA mais adequado às expectativas de sua clientela.

Baseado nas variações acima, observa-se que o fator principal referido pela clientela como responsável pela melhoria do motivo de procura foi a medicação (o remédio) recebida ou a aplicada no PAM-PA, sendo estas, respectivamente, de $89,5 \%$ no PAM e $85,6 \%$ no PA. Esses dados mostram que a clientela de ambos os serviços valoriza sobremaneira a terapêutica medicamentosa.

Essa situação do PAM poderia decorrer da ação médica que tende a priorizar o diagnóstico de processos patológicos ou poderia estar apenas refletindo uma alta prevalência de morbidade dessa clientela. Quanto aos fatores referidos como de não-melhoria do motivo de procura de ambos os serviços, verifica-se que o fator preponderante também é o medicamento (o remédio), mas com magnitude bem menor do que nos casos de melhora, sendo de $44,4 \%$ no PAM e $34,8 \%$ no PA.

Essa situação poderia sugerir que a ação "mágica" da assistência médica está paulatinamente sendo transferida do médico para o medicamento, resultando na valorização deste nos casos de melhora e na maior atribuição dos fracassos à figura do médico que "não acertou o remédio".

Verifica-se que na maioria dos sistemas anatômicos o percentual de melhoria foi maior no PA do que no PAM. Essa situação poderia ser devida a que o PA, por sua origem e forma de organização, seria mais eficiente para resolução de casos agudos, ou mesmo pode ser atribuída a diferenças no tipo de queixas apresentadas por ambas as clientelas que, embora classificadas no mesmo sistema anatômico, podem apresentar gravidade e tipo de evolução distintos.

Ao se estudar especificamente a resolutividade referida pelos clientes que utilizaram os serviços pela primeira vez, verifica-se que dos 18 clientes (14,7\% da amostra) do PAM apenas 6, correspondentes a $33,3 \%$ daqueles, referem melhora da quei$x a$, enquanto no $P A$ os 8 clientes ( $6,3 \%$ da amostra) de primeira vez referem melhora da queixa, correspondendo a $100,0 \%$ dos clientes de primeira vez. Essa situação sugere maior eficiência do PA para 0 atendimento dessa demanda, enquanto 0 PAM, por estar voltado para ações médico-sanitárias programadas, não tem a mesma adequação.

Apesar das dificuldades em analisar a satisfação da clientela frente ao atendimento recebido, devido à multidimensionalidade dessa variável $^{13}$, o presente trabalho optou por abordar a satisfação da clientela do ponto de vista do relacionamento desta com a instituição e não apenas à relação médico-paciente. A maioria da clientela

TABELA 4

Número e percentagem segundo informaçōes sobre melhoria do motivo de procura eárea de atendimento do PAM-PA Jardim São Jorge, no período de outubro de 1985 a março de 1986.

\begin{tabular}{lrrrrrrr}
\hline $\begin{array}{l}\text { Melhoria do } \\
\text { Motivo }\end{array}$ & $\mathrm{n}^{2}$ & PAM & $\%$ & $\mathrm{n}^{\circ}$ & PA & $\mathrm{n}^{2}$ & Total \\
\hline Sim & 86 & 70,5 & 104 & 81,9 & 190 & 76,3 \\
Não & 36 & 29,5 & 23 & 18,1 & 59 & 23,7 \\
\hline Total & 122 & 100,0 & 127 & 100,0 & 249 & 100,0 \\
\hline
\end{tabular}

$\chi^{2}=7,613$

$\chi^{2}$ crit $=3,841$ 
de ambos os serviços considera-se satisfeita com o atendimento recebido, $86,0 \%$ no PAM e $82,0 \%$ no PA. No entanto, ao analisar as informações fornecidas sobre a não satisfação com o atendimento, esta se apresenta maior no PAM $(14,0 \%)$ do que no PA $(8,0 \%)$ e é estatisticamente significativa. Um dos fatores importantes de "não satisfação" refere-se à demora de atendimento no PAM, sugerindo que a população, menos favorecida, se sujeita a despender mais tempo para conseguir melhor relacionamento interpessoal e/ou acesso mais fácil às ações assistenciais desenvolvidas pelo PAM. Poderia também sugerir que, apesar de o serviço público não cobrar "honorário" de sua clientela, esta pagaria uma parcela de seu tempo para receber os diferentes tipos de serviços, sendo esta mais "onerosa" no PAM do que no PA.

\section{COMENTÁRIOS}

Para melhor compreensão dos resultados encontrados no estudo da clientela do PAM-PA Jd. São Jorge, faz-se necessário conhecer os objetivos e a forma de organização desses, que são distintos em sua essência.

O PA, buscando atender o mais rápido possível ao episódio agudo, apresenta um processo de trabalho desburocratizado, o qual exige apenas registros sumários e controle simples das açōes. Dessa maneira permite um rápido acesso da clientela ao médico è medicação correspondente. O PAM, buscando reordenar a demanda e efetuar o controle de saúde da clientela, desenvolve um processo de trabalho do qual participam outros trabalhadores da saúde, além do médico, resultando maior complexidade do atendimento. Este se apresenta fragmentado e em cada etapa há preocupação com o processo educativo, visando à mudança de comportamento que permita a reordenação da demanda, exigindo registro mais detalhado das ações e acarretando maior dispêndio de tempo para execução das atividades previstas.

O estudo efetuado no PAM-PA Jd. S. Jorge mostra que a integração da assistência médica à rede básica de serviços da SHS, efetivada por meio da implantaçăo de um serviço de pronto atendimento junto a um PAM, concretizou-se como um serviço complementar às ações de assistência médicosanitária próprias do PAM, o qual não respondia às necessidades de saúde sentidas pela população usuária.

Para que a integração de serviços se constitua numa real estratégia para a implantação do Sistema Único de Saúde ${ }^{8}$ e viabilizador da etapa estratégica dos Sistemas Unificados Descentralizados de Saúde (SUDS) ${ }^{10}$ será necessária a elaboração de uma nova programação que atenda às necessidades de saúde sentidas pela população e que, a partir desse princípio básico, seja capaz de propor e executar açōes visando à integralidade da saúde do indivíduo.

Para um atendimento satisfatório será necessário que a base da nova programação deixe de ser essencialmente administrativa, visando à racionalização de recursos, maior eficiência e controle do processo ou mesmo o "enquadramento técnico" da demanda. Será necessário, para a nova programação, maior conhecimento das queixas apresentadas, das características biologicas e sociais e que sejam contemplados os anseios da população usuária, principalmente no que se refere à expectativa desta em relação aos serviços a serem oferecidos.

Essa nova programação deverá permitir o atendimento rápido e desburocratizado da clientela que procura o serviço com queixas por problemas patológicos, facilitando o acesso ao profissional médico, bem como propiciar o necessário atendimento contínuo da clientela, de maneira a garantir a visão integral do processo saúde-doença. Para que essa programação tenha maior grau de resolutividade será necessário que o sistema disponha ou tenha acesso aos recursos tecnológicos disponíveis na rede hospitalar, sem os quais a capacidade resolutiva estará restrita à propedêutica clínica, que se encontra na prática profundamente alterada pelo processo de trabalho em vigor ${ }^{12,21}$. Deverá, também, permitir que as ações assistencialistas compensatórias de caráter social, desempenhadas pela. saúde pública nas últimas décadas, sejam acompanhadas de ações mais condizentes com as condições sócio-econômicas do cliente e, conseqüentemente, sejam mais efetivas para os objetivos a que se destinam. 
TANAKA, O.Y. \& ROSENBURG, C.P. [Analysis of the use of a public health dinics of the Department of Health of the city of S. Paulo, Brazil]. Rev. Saúde públ., S.Paulo, 24: 60 - 8, 1990.

ABSTRACT: A working proposal for the integration of the activities of public health assistance is presented. Two health clinics in the city of S. Paulo, Brazil, were studied. Taking as a starting-point that all activity in the health sector depends on community participation, this study sought to discover how the population has received and used the geographically integrated health services. For this purpose, information was collected from the users of both of these services, by means of a questionnaire, as to the motive for the use of the service, the service's ability to meet the need, the degree of usersatisfaction, etc. The analysis of the above information as well as of the objective and the working method of these services, leads to the conclusion that they are used by the public in a selective way for the purpose of meeting immediate needs related to present illnesses.

KEYWORDS: Primary health care. Health services needs and demand. Consumer satisfaction.

\section{REFERÊNCIAS BIBLIOGRÁFICAS}

1. BALDŨ̃O, M.F.A. et al. Alguns aspectos metodológicos de um levantamento de motivos de procura em unidades básicas de saúde. São Paulo, Secretaria de Higiene e Saúde do Município de São Paulo, 1985. [Mimeografado].

2. BRAGA, S.C.S. \& PAULA, S.G. de. Saúde e previdência: estudos de política social. São Paulo, Cabes-Hucitec, 1981.

3. CARVALHEIRO, J.R. Levantamento de saúde por entrevistas domiciliares. Ribeirão Preto, 1975. [Tese de Livre Docência - Faculdade de Medicina de Ribeirão Preto da USP].

4. CLASSIFICAÇÃO Intemacional de Assistência Primária (CIAP). [s.n.t. - Mimeografado].

5. CONFERENCIA INTERNACIONAL SOBRE CUIDADOS PRIMÁRIOS DE SAUUDE, Alma-Ata, URSS, 1978. Relatorio final. Brasília, OMS/UNICEF, 1979.

6. CONFERENCIA NACIONAL DE SAUDDE, 5*, Brasilia, 1975. Anais. Brasília, Ministério da Saúde, 1975.

7. CONFERENCIA NACIONAL DE SAUDE, 7*, Brasilia, 1980. Anais. Brasilia, Ministério da Saúde, 1980.

8. CONFERENCIA NACIONAL DE SAUUDE, 8:, Brasília, 1986. Anais. Brasília, Ministério da Saúde, 1986.

9. DECRETO-LEI $n^{2} 4.682$ de $24 / 01 / 1923$ apud BRAGA, J.C.S. \& PAULA, S.G. ${ }^{2}$

10. DECRETO n 94.657 de 20/07/1987. In: Ministério da Previdência e Assistência Social. SUDS Sistemas Unifica. dos e Descentralizados de Saúde nos Eslados. Brasilia, 1987. p. 12.

11. DIXON, W.J. \& MASSEY, F.J. Introduction to statistical analisys. New York, McGraw-Hill, 1957.

12. GONÇALVES, R.B.M. Tecnologia e organização social das práticas de saúde: características tecnológicas do processo de trabalho na rede estadual de centros de saúde de São Paulo. São Paulo, 1986. [Tese de Doutoramento - Faculdade de Medicina da USP].

13. LINDER-PELZ, S. \& STRUENING, E.L.The multidimensionality of patient satisfation with a clinic visit. $J$. Community Hllh, 10: 42-54, 1985.

14. LUZ, M.T. As instituiçōes no Brasil: instituiçäo 'e estraté. gia de hegemonia. Rio de Janeiro, Ed. Grad, 1979.

15. MNISTÉRIO DA PREVIDÊNCIA E ASSISTÊNCIA SO. CIAL. Reorientação da assistência d̀ saúde no ámbito da previdência social. $3^{2}$ ed. Brasilia, 1983.

16. MINISTÉRIO DA SAUUDE/MINISTÉRIO DA PREVIDÊNCIA E ASSISTENCIA SOCIAL/MINISTÉRIO DO INTERIOR/SECRETARIA DE PLANEJAMENTO DA PRESIDENCIA DA REPÚBLICA. Programa Nacional de Serviços Básicos de Saúde PREV-SAÚDE. Brasília, 1980. [Doc. versão preliminar].

17. OLIVEIRA, J.A. de A. \& TELXEIRA, S.M.F. (IM) previdência social: 60 anos de história da previdéncia no Bra. sil. Petrópolis, Ed. Vozes, 1985.

18. RAMOS, R. A integração sanitária: doutrina e prática. São Paulo, 1972. [Tese de Livre-Docência — Faculdade de Saúde Pública da USP].

19. SANTOS, W.G. Cidadania e justiça: a política social na ordem brasileira. Rio de Janciro, Ed. Campus Lıda, 1979.

20. TAKEDA, S.M.F. et al. Estudo dos motivos de consulta em uma vila na perifcria de Porto Alegre. Rev. Ass. Med. R.G.S., 29: 231-9, 1985.

21. TANAKA, O.Y. Avaliação do programa de assistência à criança da Secretaria da Saúde de São Paulo. São Paulo, 1983. [Disscrtação de Mestrado — Faculdade de Saúde Pública da USP].

Recebido para publicação em 13/7/1989 Aprovado para publicação em $7 / 11 / 1989$ 